\title{
Deterioration of Cardiac Function After Acute Myocardial Infarction is Prevented by Transplantation of Modified Endothelial Progenitor Cells Overexpressing Endothelial NO Synthases
}

\author{
Xiang Chen ${ }^{a, c}$ Mingbiao Gua, ${ }^{a, b}$, Xianxian Zhao ${ }^{a}$ Xing Zheng ${ }^{a}$ Yongwen Qin ${ }^{a}$ Xiaohua You \\ aDepartments of Cardiology, ChangHai Hospital, Second Military Medical University, Shanghai; \\ ${ }^{b}$ Departments of Cardiology, YanCheng First People's hospital, Yancheng, Jiangsu Province; \\ 'Xiang Chen and Mingbiao Gu contributed equally to this article
}

\section{Key Words}

Endothelial progenitor cells - Endothelial NO synthases - Acute myocardial infarction - Cell transplantation

\begin{abstract}
Background/Aims: Stem cell transplantation and gene therapies have been shown to attenuate myocardial dysfunction after myocardial infarction (AMI) in different acute and chronic animal models. The aim of this study was to assess the potential therapeutic efficacy of endothelial NO synthases (eNOS)-expressing endothelial progenitor cells (EPCs) on infarcted hearts. Methods: Lentiviral eNOS-infected EPCs were injected after $1 \mathrm{~h}$ of ligation of the left anterior descending artery (LAD). The pro-inflammatory cytokines TNF- $\alpha$ and IL-1 $\beta$ levels in cardiac tissue were measured by ELISA at 3 days after transplantation. 28 days post AMI (before sacrifice), Left ventricular function of each group was determined by echocardiography and pressure-volume system. Cardiac tissues were analyzed with hematoxylin and eosin $(\mathrm{H} \& \mathrm{E})$ staining and immunohistochemisty. eNOS expression in cardiac tissues was detected by western blot, and NO production of cardiac tissues was determined using an NO assay kit. Results: TNF- $\alpha$ and IL-1 $\beta$ levels in cardiac tissue were decreased significantly at 3 days after transplantation of lentiviral with eNOS infected EPCs compared to medium control, eNOS lentiviral vector and normal EPCs. At the 28 day after AMI, echocardiography and hemodynamic measurements, and isolated heart studies showed great therapeutic efficacy in improvement of cardiac function, reduction of infarcted size and improvement of vascular
\end{abstract}


densities in the peri-infarct region after intramyocardial application of lentiviral eNOS-infected EPCs compared to medium control, eNOS lentiviral vector and normal EPCs. The eNOS overexpression in cardiac tissue was observed in the eNOS-EPCs and eNOS lentiviral vector group, and NO levels were increased significantly in the eNOS-EPCs and eNOS lentiviral vector group compared to the other three groups (sham operated group, transplantation of medium or EPCS group). Conclusion: EPCs can be an attractive vehicle for the exogenous eNOS expression into heart after infarction, which is beneficial to prevent deterioration and promote restoration of cardiac function after AMI by improving angiogenesis.

Copyright $\odot 2013$ S. Karger AG, Basel

\section{Introduction}

Cardiovascular disease is the major cause of death throughout the world [1]. Heart failure caused by acute myocardial infarction (AMI) is the major factor of disease caused death in the world[2]. AMI occurs most when there is a rupture of coronary artery which contains an atherosclerotic plaque, and that may cause thrombosis and occlusion of the artery, stop the blood supply in that region of heart and cause necrosis of the affected area [3]. Although cardiogenic stem cells have been proven to reside in the heart, their number is severely limited[4]. Moreover, the rate of its proliferation is slow and can rarely meet the demand for tissue regeneration after severe myocyte damage. So, stem cell transplantation[5] as well as gene therapies[6] turned to be promising strategies in the treatment of AMI since they can replenish the myocyte number and stimulate angiogenesis.

Endothelial progenitor cells (EPCs) existing in bone marrow (BM) and peripheral blood have high proliferative potential and could form neovascularization to a limited extent [79]. In vitro, EPCs can differentiated into endothelial lineage cells, and in animal models of ischemia, EPCs are shown to incorporate into sites of active neovascularization [1012]. Endothelial nitric oxide synthase (eNOS) and its bioactive product nitric oxide (NO) are well-established proangiogenic molecules [13]. eNOS-derived NO regulates cardiac myocyte function, myocardial neovascularization, and myocardial perfusion. Whereas, the bioavailability of eNOS-derived NO is severely reduced in both experimental myocardial infarction and in humans with heart failure $[14,15]$. Transplantation of modified cells expressing eNOS could be an attractive alternative for NO production in tissues.

In this study, we investigated our hypothesis that restoration of NO availability by transplantation of modified EPCs expressing eNOS could reduce infarction area and improve cardiac function. An important aspect of this study was to delineate the advantage of EPCs carrying eNOS as origin of NO production during cardiac repair.

\section{Materials and Methods}

\section{Ethic statement}

The study protocol was approved by the medical ethics committee of Shanghai Changhai Hospital, conforms to the Principles of Laboratory Animal Care (National Society for Medical Research), and was conducted according to National Institutes of Health guidelines.

Preparation of EPCs and cell culture

For culture of mouse EPCs, BM-mononuclear cells from C57BL/6 mouse were collected by density gradient centrifugation with Ficoll-Isopaque Plus (Histopaque-1077, Sigma) and were plated at a density of 0.8-1.0 $\times 10^{6}$ cells $/ \mathrm{cm}^{2}$ on mouse plasma vitronectin-coated (Sigma-Aldrich) dishes with EC basal medium (EBM, Cambrex) supplemented with 10\% fetal bovine serum (FBS, Logan, UT), $50 \mu \mathrm{g} / \mathrm{mL}$ ascorbic acid, 100 units $/ \mathrm{mL}$ penicillin, and $100 \mu \mathrm{g} / \mathrm{mL}$ streptomycin. Incubation was carried out at $37^{\circ} \mathrm{C}$ in a $5 \% \mathrm{CO}_{2}$ incubator. Nonadherent cells were removed, and medium was replaced with fresh medium at day 4 . The cells were maintained through day 7 and used as an EPC-enriched population. 
Cellular staining

Four days after culture, EPCs, recognized as attaching spindle-shaped cells, were assayed by costaining with FITC-labeled Ulex europaeus agglutinin (UEA)-1 (Sigma) and 1,1'-dioctadecyl-3,3,3',3'tetramethylindocarbocyanine (DiI)-labeled acetylated low density lipoprotein (acLDL; Biomedical Technologies, Stoughton, MA). Cells were first incubated with acLDL at $37^{\circ} \mathrm{C}$ and later fixed with $1 \%$ paraformaldehyde for $10 \mathrm{~min}$. After washes, the cells were reacted with FITC-UEA-1 $(10 \mu \mathrm{g} / \mathrm{ml})$ for $1 \mathrm{~h}$. After that, cells were detected with an inverted fluorescent microscopy (Nikon) that which demonstrating double-positive fluorescence was identified as EPCs.

\section{Flow cytometric analysis}

The identity of EPCs is based on the principle of flow cytometry analysis (2-parameter, single-color and 15-mW argon laser; Becton Dickinson, CA) by assessing the surface markers. FITC-conjugated antiCD34, anti-CD45, PE-conjugated anti-CD133 and anti-KDR antibodies (Jackson IRL, Baltimore, MD) were used. CD34+/CD133+/KDR+/CD45- cells were identified as EPCs. The data were collected from 20,000 cells for each sample and analyzed with CellQuest software (Becton Dickinson, CA).

\section{Lentivirus infection}

Human eNOS cDNA was cloned by Polymerase Chain Reaction (PCR), and then eNOS cDNA was subcloned into lentiviral vectors pPRIME-CMV-GFP-FF3 carrying Green Fluorescent Protein (GFP) as reporter. The recombinant lentivirus with eNOS was produced by co-transfection of HEK293T cells with plasmids pPRIME-CMV-eNOS, lenti-eNOS-GFP virus was added to EPCs dishes when the EPCs were about $60 \%$ confluence. Viral infection was carried out at $37^{\circ} \mathrm{C}$ in a $5 \% \mathrm{CO}_{2}$ incubator for $12 \mathrm{~h}$ with the virus concentration was 10 MOIs. The empty lentiviral vector lenti-GFP was used as negative control. Three days after viral infection, EPCs were collected and examined to detect the level of eNOS by using western blot and RT-PCR.

\section{Western blotting analysis}

Radio-immunoprecipitation assay buffer (Beyotime, Shanghai, China) was used to extract protein from EPCs (or EPCs overexpressing eNOS or carrying empty lentiviral vector) or cardiac tissue. The protein expression was measured by western blot. In brief, the total protein concentration was determined by the BCA protein Assay Kit (Beyotime). Protein was separated by 8\% 15\% sodium-dodecylsulphatepolyacrylamide gel electrophoresis (SDS-PAGE). Then, protein was transferred to nitrocellulose membranes (Amersham Bioscience, Piscataway, NJ) and incubated with the antibodies (eNOS, 1:1000 and GAPDH, 1:5000, all purchased from Santa Cruz Biotechnology, Santa Cruz, CA, USA). After that, the membrane was washed with $50 \mathrm{mM}$ PBS with $0.05 \%$ Tween (PBS-T, pH 7.6) three times and incubated for $1 \mathrm{~h}$ at room temperature with peroxidase cojugated IgG. The level of GAPDH was analyzed in parallel as a normalized control.

\section{Reverse transcription polymerase chain reaction (RT-PCR)}

Total cellular RNAs were extracted using Trizol $^{\mathrm{TM}}$ reagent (Invitrogen, Carlsbad, CA) according to the manufacturer's protocol. RNA $(0.2 \mu \mathrm{g})$ was reverse transcribed using the High Capacity cDNA synthesis kit (Applied Biosystem, California, USA) according to the manufacturer's instructions. Human eNOS CDNA (Accession: NM_000603) was amplified using primers 5'-CTT TGC TCG TGC CGT GGA CA-3' and 5'-GCC CTC GTG GAC TTG CTG CT-3'. Mouse GAPDH cDNA served as housekeeping gene (Accession: NM_008084) and was amplified in parallel with the target gene using primers 5'-ATT GTC AGC AAT GCA TCC TG-3' and 5'-ATG GAC TGT GGT CAT GAG CC-3'. PCR conditions consisted of: $94{ }^{\circ} \mathrm{C}$ for $5 \mathrm{~min}, 30$ cycles of: $94{ }^{\circ} \mathrm{C}$ for $30 \mathrm{sec}$, annealing temperature (eNOS: $54^{\circ} \mathrm{C}$ and GAPDH: $56^{\circ} \mathrm{C}$ ) for $30 \mathrm{sec}, 72^{\circ} \mathrm{C}$ for $1 \mathrm{~min}$. A final 10-min extension at $72{ }^{\circ} \mathrm{C}$ was done at the end. Products were analyzed on $1.5 \%$ agarose gel.

\section{AMI models preparation and cell transplantation}

The EPCs were digested with trypsase, followed by centrifugation at $37^{\circ} \mathrm{C} 3000 \mathrm{rpm}$ for $15 \mathrm{~min}$. The supernatant was removed, and FBS-free medium was added into the cell pellet. Then the cell suspension was filtered with a $25-\mu \mathrm{m}$ sieve to eliminate the clumped cells. Before injection, the EPCs suspension was examined under a microscope to ensure no evident cell mass in the suspension. 
6-10-weeks-old C57BL/6 mice were provided by Shanghai Changhai Hospital and underwent myocardial ischemia by occluding the left coronary artery as described previously [16]. Briefly, mice were anesthetized with an intraperitoneal injection of avertin $(0.014 \mathrm{mg} / \mathrm{kg} ; 2,2,2$-Tribromoethanol; Sigma), the chest was opened and the ribs were gently spread. Ligation of the left anterior descending artery (LAD) was performed 1 to $2 \mathrm{~mm}$ distal to the line between the left border of the pulmonary conus and the right border of left atrial appendage, and then the heart was repositioned to the chest. Animals were assessed by echocardiography to make sure that acute myocardial infarction (AMI) models were prepared successfully. Experimental animals were randomized for sham operated group (sham, $n=15$ ), medium control group (medium, $\mathrm{n}=15$ ), eNOS lentiviral vector injection group (lenti-eNOS, $\mathrm{n}=15$ ), control EPCs transplant group (EPCs, $\mathrm{n}=15$ ), and eNOS-EPCs transplant group (eNOS-EPCs, $\mathrm{n}=15$ ). The transplantation was performed at $1 \mathrm{~h}$ after induction of AMI. Multiple intramyocardial injections of $20 \mu \mathrm{l}$ basal medium or eNOS lentiviral vector without cells, or cell suspension containing $1 \times 10^{5} \mathrm{EPCs}$ (or eNOS-EPCs) were carried out in the free wall of the left ventricle (LV).

Enzyme-linked immunosorbent assay (ELISA) analysis

At the day 3 after transplantation (additional experiment, $n=5$ of each group), mice were humanely sacrificed and the hearts were removed. The ELISA kit (R\&D System, Minneapolis, MN, USA) was used for determination of pro-inflammatory cytokines TNF- $\alpha$ and IL-1 $\beta$ levels in cardiac protein according to manufacturer instruction. Tissues from infarcted area of transplant groups or anterior left ventricular of sham operated group were homogenized in ice-cold PBS buffer containing protease inhibitor cocktail (21 $\mathrm{mmol} / \mathrm{L}$ leupeptin and $3.1 \mathrm{nmol} / \mathrm{L}$ aprotinin), and total proteins were extracted using a protein extraction kit (Pierce, Rockford, IL, USA). Total protein concentration was determined using a protein assay kit (Pierce, Rockford, IL, USA).

\section{Echocardiography}

All mice were anaesthetized by intraperitoneal injection with ketamine $(5 \mathrm{mg} / 100 \mathrm{~g})$. Transthoracic echocardiography was performed using a Vevo770 imaging system (VisualSonics Inc., Toronto, Ontario, Canada) with a 30-MHz probe. We measured the left ventricular (LV) end-diastolic and end-systolic areas at two-dimensional mode and the LV end-diastolic diameter (LVEDD) and LV end-systolic diameters (LVESD) at one-dimensional mode, as described previously [17]. LV fractional shortening (FS) was calculated following formula: FS $(\%)=($ LVEDD - LVESD $) / L V E D D \times 100$. The investigator performing and reading the echocardiogram was blinded to the treatment allocation.

\section{Hemodynamic measurements}

All mice were anaesthetized by intraperitoneal injection with ketamine $(8 \mathrm{mg} / 100 \mathrm{~g})$. The $\mathrm{LV}$ apex was punctured and a Millar catheter connected to a pressure transducer was inserted. The aortic blood pressure (BP), LV systolic pressure (LVSP), LV end-diastolic pressure (LVEDP) and the maximal rates of rise and fall in $\mathrm{LV}$ pressure $(+\mathrm{dP} / \mathrm{dt}$, $-\mathrm{dP} / \mathrm{dt})$ were recorded [17]. The measurements were made from consecutive 15 beats and averaged.

\section{Histological analysis}

After the 28-day echocardiographic and hemodynamic measurements, all mice were humanely sacrificed. Hearts were cut into three transverse segments, fixed in $10 \%$ formaldehyde and embedded in paraffin. Section were cut at 10- $\mu \mathrm{m}$ from each segment, and stained with hematoxylin and eosin (H\&E). Then 3-4 sections from each heart were scanned on both surfaces using a digital flatbed scanner. The infarcted size was measured digitally using Image Pro Plus software (Media Cybernetics). The infarct size was presented as percentage of the $\mathrm{LV}$.

To quantify the vessel density in the per-infarct area, other sections were incubated with $0.6 \% \mathrm{H}_{2} \mathrm{O}_{2}$, and permeabilized with $0.2 \%$ Triton X-100 for 5 min. After blocking with $1 \%$ fish gelatin (Sigma) for 1 hour at room temperature, the sections were incubated with a rabbit anti-mouse monoclonal factor VIII antibody (1:2000; Zymed, San Francisco, CA, USA) overnight at $4^{\circ} \mathrm{C}$, then washed with PBS three times, and incubated with goat anti-rabbit IgG (1:500; Santa Cruz, CA, USA). The sections were colored with streptABComplex/ horseradish peroxidase Duet kit (Dako Ltd., Cambridge, UK) and counterstained with hematoxylin. Vessels 
were counted in 5 fields in the per-infarct zone at magnification of 200x. The number of vessels per unit area $\left(\mathrm{mm}^{2}\right)$ was determined using Image Pro Plus software (Media Cybernetics) to evaluate light micrographs.

\section{NO measurements}

The amount of NO in cardiac tissue was determined using an NO assay kit (Beyotime, Shanghai, China) according to the manufacturer's protocol. Briefly, tissue samples from the risk area were rinsed, homogenized in deionized water (1:10, wt/vol), and centrifuged at $14000 \mathrm{~g}$ for 10 minutes. The absorbance was measured with a microplate reader (BioRad, Hercules, CA, USA) at $550 \mathrm{~nm}$ after enzymatic conversion of the supernatant nitrate to nitrite by nitrate reductase, and supernatant NO levels were determined by colorimetric assay.

\section{Statistical analysis}

All data were presented in means \pm standard deviations (SD). Statistical comparisons between two groups were done using the $t$-test and among multiple groups by ANOVA. The level of significance was determined through value of $P<0.05$.

\section{Results}

\section{Properties of EPCS}

EPCs phenotype was confirmed by the presence of double positive cells for acLDL and UEA-1 (Fig. 1A). Flow cytometric analysis showed that EPCs were positive for their surface markers CD34, CD133 and KDR, but negative for CD45 before (Fig. 1B) and after (Fig. 1C) transfection of eNOS lentiviral vector.

\section{Characterization of EPCs transduced with eNOS lentiviral vector}

eNOS expression was forced in EPCs by transfection with lentivirus. A lentiviral vector pPRIME-CMV-GFP-FF3 carrying GFP was used. To package the lentiviral vector containing eNOS, pPRIME-CMVGFP-FF3 carrying eNOS and three helper plasmids were co-transfected into HEK293T cells; $48 \mathrm{~h}$ later, almost 90\% cells were GFP positive (Fig. 2A, B). Then the packaging cell supernatant was collected, concentrated and used to infect EPCs. The empty lentivirus was used as a negative control. Forced eNOS expression was validated, as shown by western blot with an anti-eNOS antibody and RT-PCR (Fig. 2C, D), while no eNOS overexpression was seen in cells infected with the control lentiviral vector.

Improvement of myocardial repair after infarction by transplantation of eNOS-EPCs

To evaluate the potential of eNOS-EPCs on myocardial repair, we evaluated the functional consequence of transplantation of eNOS-EPCs mouse AMI model in vivo. After induction of myocardial infarction by permanent occluding the left anterior descending coronary artery (Table 1), medium, eNOS lentiviral vector, EPCs, and eNOS-EPCs were implanted into the infarcted area.

At the day 3 after transplantation, the levels of TNF- $\alpha$ and IL-1 $\beta$ in the infarcted zone decreased significantly in the eNOS-EPCs group compared with the other three transplant groups (Fig. 3A and B). However, the levels of TNF- $\alpha$ and IL-1 $\beta$ in the infarcted zone of eNOSEPCs group were remained increased significantly when compared with sham operated group. At the day 28 after AMI, mice in eNOS-EPCs transplant group exhibited a significant $(p<0.05)$ decrease of mortality compared with sham operated group. However, transplantation of eNOS-EPCs significantly $(p<0.05)$ increased surviving rate compared with the other transplant groups, and survival was increased by $40 \%$ in the eNOS-EPCs group compared to medium group (Fig. 4A). Left ventricular function was measured by echocardiography and pressure-volume system at day 28 after AMI (before sacrifice). Mice displayed significant LV remodeling, including reduced LV dimensions and increased fractional shortening in the three transplant groups compared with the medium control group (Table 2). Moreover, fractional shortening decreased from $30.1 \%$ to $22.4 \%$ in the medium control group from $1 \mathrm{~h}$ 
A
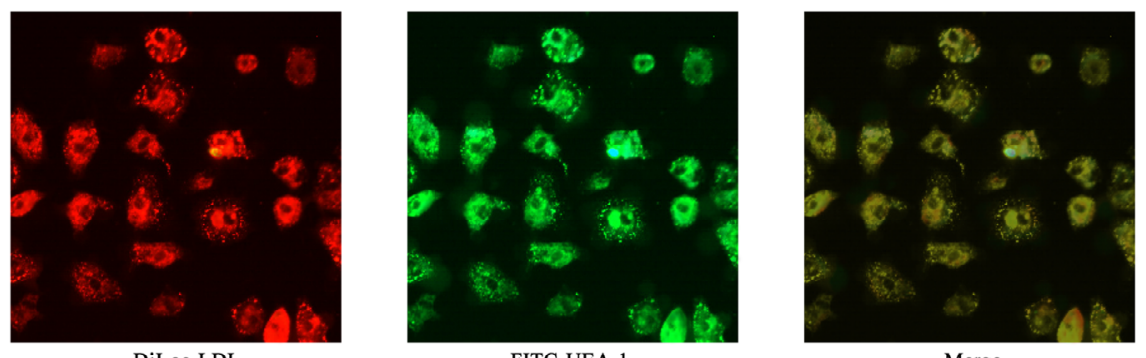

B
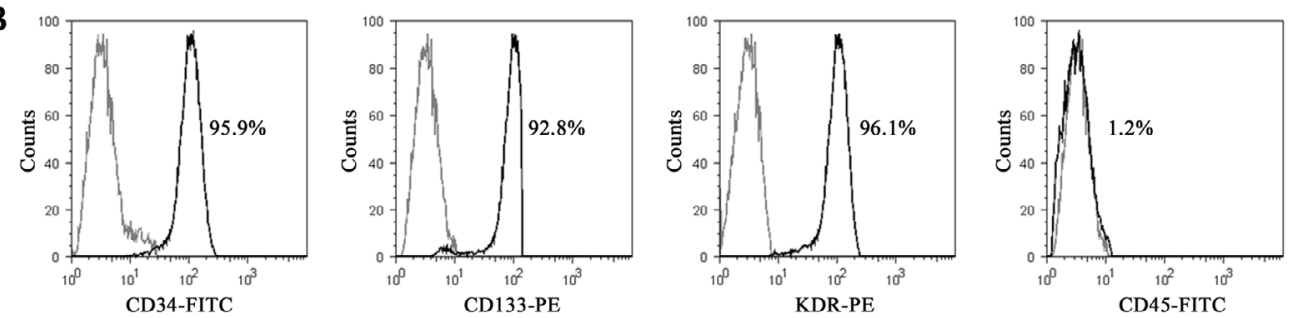

C
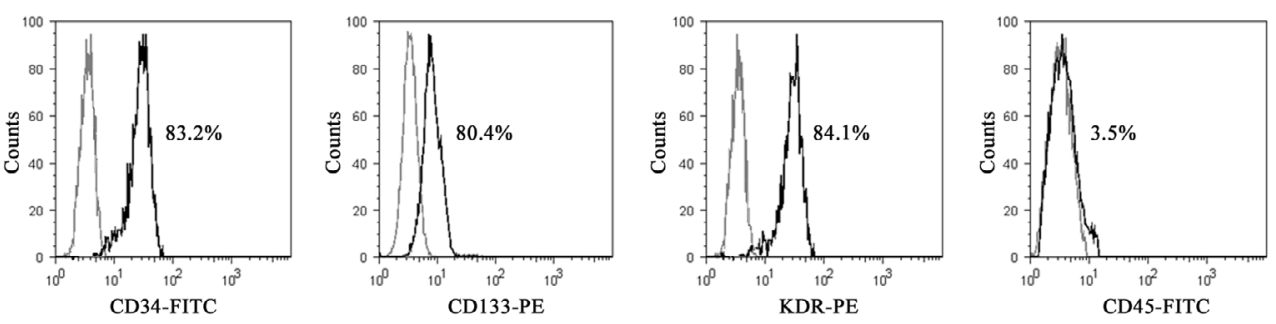

Fig. 1. Identification of EPCs. (A) Confirmation of EPC phenotype by co-staining with DiI-ac-LDL and FITCUEA-1 (200x). Before (B) and after (C) eNOS lentiviral vector transfection, staining of CD34/CD133/KDR/ CD45 (black lines) by flow cytometry analysis is shown compared with isotype controls (gray lines).

Fig. 2. Lentiviral vector-mediated eNOS overexpression in EPCs. (AB) Package of the lentiviral vector (100x). The lentiviral vector pPRIME-CMV-GFP-FF3 was cotransfected into HEK293T cell with three helper plasmids, 48 $\mathrm{h}$ after transfection, almost $90 \%$ cells were GFP positive. eNOS overexpression level in EPCs after infect with lentiviral vectors (C, RNA and D, protein).

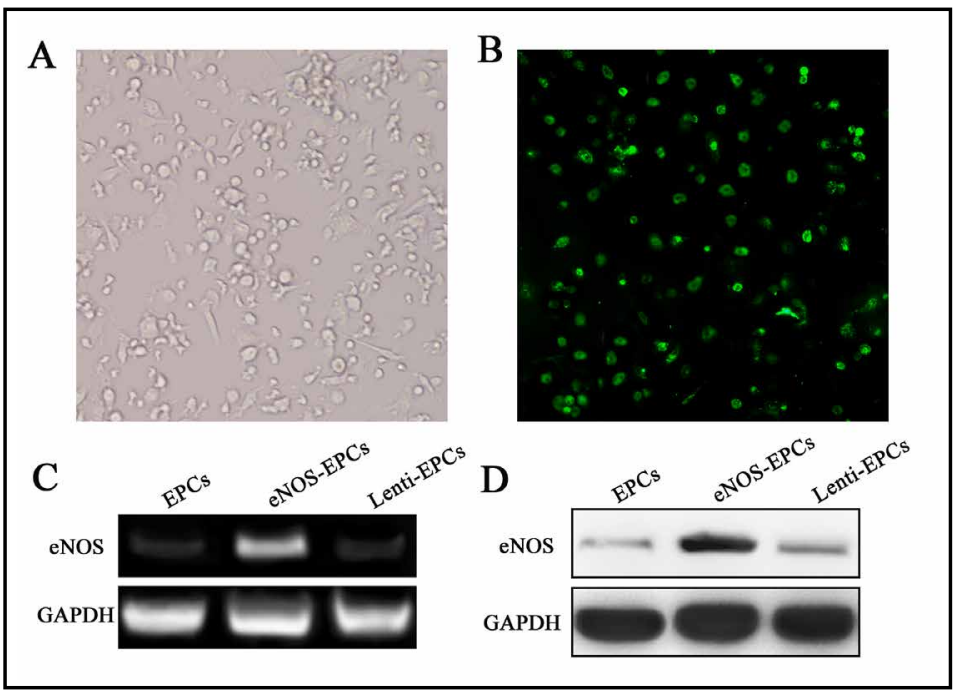

to 28 days post AMI, but was maintained at $33.8 \%$ in the eNOS-EPCs group (Table 1 and 2), which showed that eNOS-modified EPCs transplantation administered at $1 \mathrm{~h}$ after induction of AMI prevented the further deterioration of cardiac function that occurred between 1 hour and 28 days following AMI. Consistently, medium control group animals showed a significant reduction of $+\mathrm{dP} / \mathrm{dt}$ and $-\mathrm{dP} / \mathrm{dt}$ compared with the three transplant groups. Importantly, myocardial function was significantly improved in eNOS-EPCs transplant group 
Table 1. Echocardiography data of sham and AMI mice before transplantation. BW, body weigh; HR, heart rate; LV, left ventricular; LVEDD, LV end-diastolic dimension; LVESD, LV end-systolic dimension; FS, fractional shortening. Data are expressed as mean \pm SD. ${ }^{*} \mathrm{p}<0.05$ v.s. Sham group.

\begin{tabular}{ccc}
\hline & Sham & AMI \\
\hline BW $(\mathrm{g})$ & $21.60 \pm 0.84$ & $22.38 \pm 0.64$ \\
HR $(\mathrm{bpm})$ & $372.5 \pm 41.1$ & $358.1 \pm 54.7$ \\
LVEDD $(\mathrm{mm})$ & $4.02 \pm 0.17$ & $4.26 \pm 0.21$ \\
LVESD $(\mathrm{mm})$ & $2.39 \pm 0.13$ & $2.98 \pm 0.19^{*}$ \\
FS $(\%)$ & $40.55 \pm 1.25$ & $30.05 \pm 1.03^{*}$ \\
\hline
\end{tabular}

\begin{tabular}{|c|c|c|c|c|c|}
\hline & Sham & Medium & Lenti-eNOS & EPCs & eNOS-EPCs \\
\hline Number & 15 & 7 & 10 & 8 & 12 \\
\hline BW (g) & $28.51 \pm 0.93$ & $26.68 \pm 1.17$ & $27.42 \pm 0.69$ & $28.13 \pm 0.47$ & $27.55 \pm 0.60$ \\
\hline HR (bpm) & $359.2 \pm 38.5$ & $337 \pm 65.2$ & $362 \pm 61.0$ & $342 \pm 31.8$ & $357 \pm 58.1$ \\
\hline HW (mg) & $144 \pm 4.21$ & $137 \pm 6.94$ & $144 \pm 3.55$ & $141 \pm 7.93$ & $142 \pm 3.18$ \\
\hline LVEDD (mm) & $3.94 \pm 0.22$ & $5.71 \pm 0.13^{\ddagger}$ & $5.33 \pm 0.28 \neq \S$ & $5.63 \pm 0.15^{\ddagger \#}$ & $4.82 \pm 0.35^{*} \S \# \&$ \\
\hline LVESD (mm) & $2.41 \pm 0.18$ & $4.43 \pm 0.21^{\ddagger}$ & $3.71 \pm 0.11^{*} \S$ & $4.15 \pm 0.13^{*} \S$ & $3.19 \pm 0.24^{*} \S \# \&$ \\
\hline FS $(\%)$ & $38.83 \pm 1.14$ & $22.42 \pm 0.98^{\ddagger}$ & $30.39 \pm 1.68 \neq \S$ & $26.29 \pm 1.52 \ddagger \#$ & $33.82 \pm 1.79^{*} \S \# \&$ \\
\hline MBP (mmHg) & $112 \pm 4$ & $92 \pm 5.69^{*}$ & $105 \pm 7$ & $110 \pm 3$ & $108 \pm 5$ \\
\hline LVSP (mmHg) & $108 \pm 2$ & $79 \pm 4 \ddagger$ & $95 \pm 5^{*} \S$ & $90 \pm 4 \ddagger \S$ & $98 \pm 7^{* \S}$ \\
\hline LVEDP (mmHg) & $6 \pm 1$ & $13 \pm 2^{*}$ & $10 \pm 1$ & $11 \pm 2$ & $8 \pm 2^{\text {} \# \& \&}$ \\
\hline$+\mathrm{dP} / \mathrm{dt}(\mathrm{mmHg} / \mathrm{s})$ & $5935 \pm 483$ & $4109 \pm 353^{\ddagger}$ & $4787 \pm 113^{*} \S$ & $4318 \pm 319 \neq$ & $5086 \pm 403^{*} \S \# \&$ \\
\hline$-\mathrm{dP} / \mathrm{dt}(\mathrm{mmHg} / \mathrm{s})$ & $-4529 \pm 196$ & $-2896 \pm 216^{\ddagger}$ & $-3678 \pm 324 * \S$ & $-3149 \pm 102 \neq$ & $-4119 \pm 110^{*} \S \# \&$ \\
\hline
\end{tabular}

Table 2. Echocardiography and hemodynamics data of all mice at day 28 after transplantation. BW, body weigh; HR, heart rate; HW, heart weigh; LV, left ventricular; LVEDD, LV end-diastolic dimension; LVESD, LV end-systolic dimension; FS, fractional shortening; MBP, mean blood pressure; LVSP, LV systolic pressure; LVEDP, LV end-diastolic pressure; $+\mathrm{dP} / \mathrm{dt}$, the maximal rates of rise in $\mathrm{LV}$ pressure; $-\mathrm{dP} / \mathrm{dt}$, the maximal rates of fall in LV pressure. Data are expressed as mean \pm SD. $* p<0.05, \neq p<0.01$ v.s. Sham group, $\S p<0.05$ v.s. Medium group, \#p<0.05 v.s. Lenti-eNOS group, $\& \mathrm{p}<0.05$ v.s. EPCs group.

Fig. 3. Pro-inflammatory cytokines and eNOS expression, and NO levels in cardiac tissue. TNF- $\alpha$ (A) and IL-1 $\beta$ (B) expression analyzed by ELISA. Results are expressed as mean $\pm \mathrm{SD}$. $\mathrm{N}=5$ /group. (C) eNOS expression in myocardial tissue was confirmed by western blot. (D) NO production in myocardial tissue. Results are expressed as mean \pm SD. $\mathrm{N}=3$ /group. ${ }^{*} p<0.05$, v.s. Sham group, ${ }^{\S} p<0.05$ v.s. Medium group, ${ }^{*} p<0.05$ v.s. Lenti-eNOS group, ${ }^{\&} p<0.05$ v.s. EPCs group.

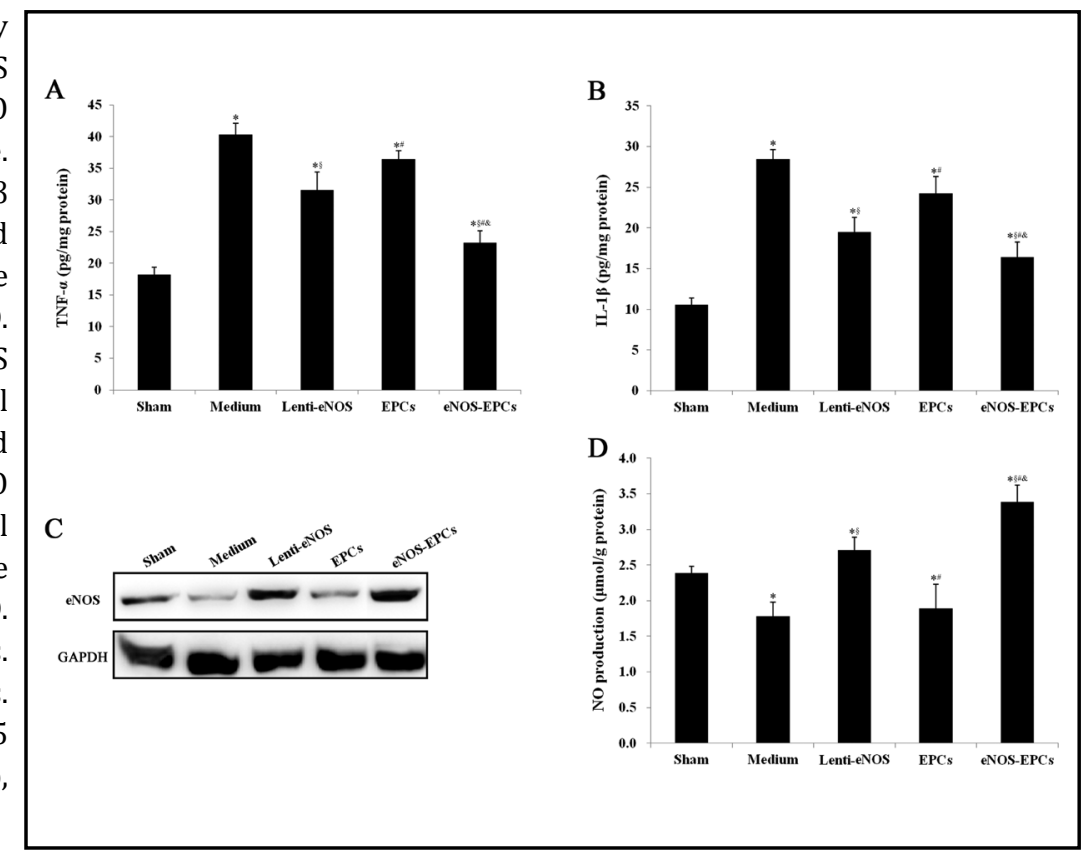

mice compared with medium control group. However, the cardiac function of eNOS-EPCs transplant group remained significantly impaired when compared with sham operated group (Table 2). The data indicated that eNOS-EPCs transplantation can significantly improve cardiac function in mice with AMI, but the treatment cannot restore normal function. 
Fig. 4. Survial curves for all groups, and measurement of infarcted size and vascular density in the peri-infarct region. (A) Mice survival curves for all groups showed a significant $(p<0.05)$ difference in eNOSEPCs group compared to the other groups, respectively. $\mathrm{N}=7-$ 15/group. (B) H\&E staining of cardiac tissue and the infarcted size was measured digitally using Image Pro Plus software. (C) Immunohistochemical staining for factor VIII in the peri-infarct region and the vascular density was measured by quantitative analyzing. Results are expressed as mean $\pm \mathrm{SD}, \mathrm{N}=4$ /group. ${ }^{\S} p<0.05 \quad$ v.s. Medium group, $" ~ p<0.05$ v.s. LentieNOS group, ${ }^{\circledR} p<0.05$ v.s. EPCs group.

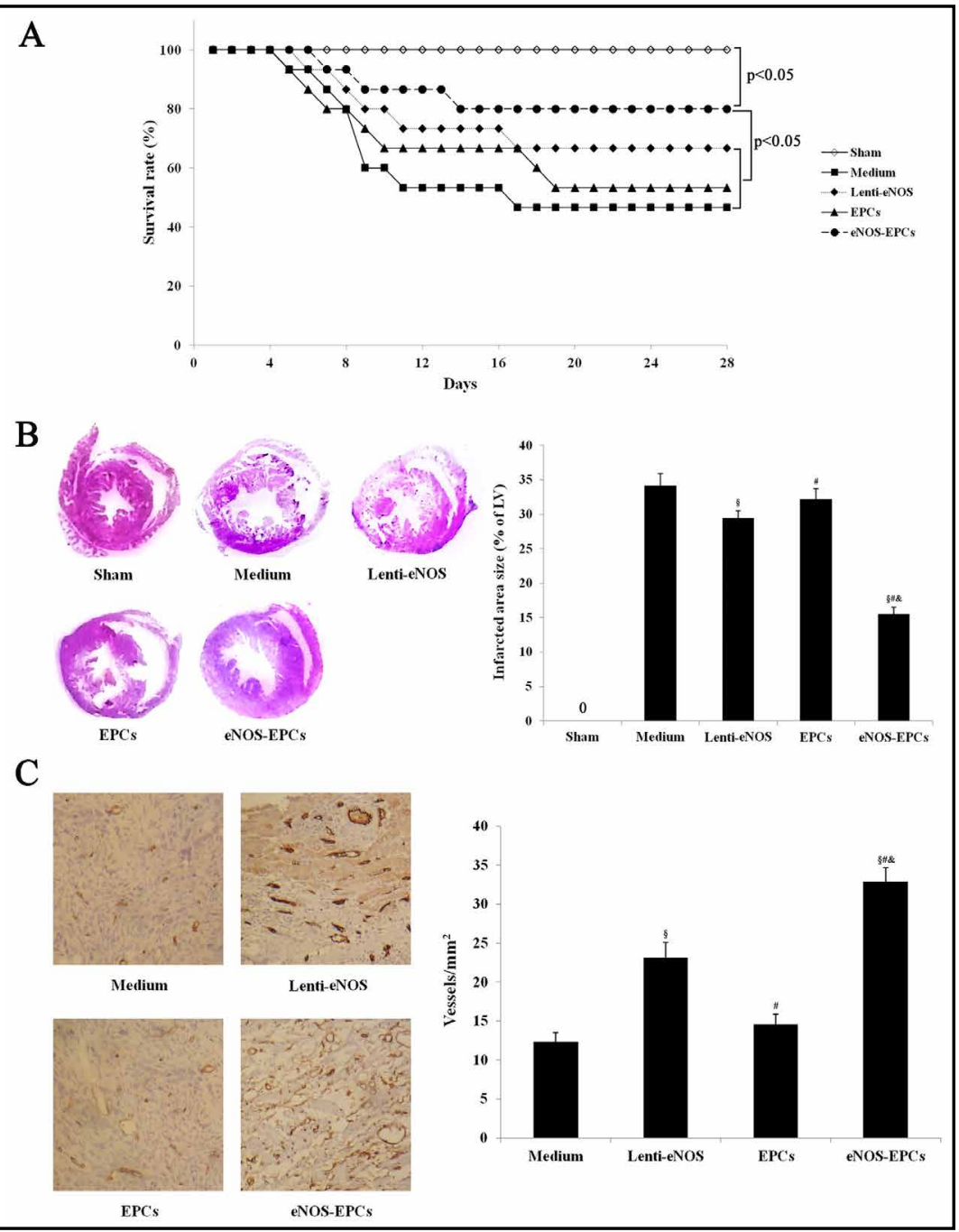

The eNOS over-expression in cardiac tissue was observed in the eNOS-EPCs and eNOS lentiviral vector groups (Fig. 3C), and NO levels were increased significantly in the eNOSEPCs and eNOS lentiviral vector group compared to the other three groups (Fig. 3D). In the histological analysis, H\&E staining of cardiac tissue revealed that the infarct size was smallest in the group that received eNOS-EPCs transplantation (Fig. 4B). Quantitative analyses also demonstrated that mice treated with eNOS-EPCs had significantly small myocardial infarct size compared with the medium control group (Fig. 4B). As shown in Figure 4C, an increased number of vessels were observed in the sections of immunohistochemical staining for factor VIII in the peri-infarct region in the three transplant groups. Thus, we can speculate that mice treated with the eNOS-EPCs transplantation significantly improve the myocardial repair in the AMI model, and myocardial repair is very likely to be mediated by improving angiogenesis and reducing inflammatory factors TNF- $\alpha$ and IL- $\beta$.

\section{Discussion}

Improvements in heart repair and reduced infarction size in AMI mice after transplantation of eNOS-EPCs are the paramount finding of this study. It is speculated that the improvements in cardiac repair are a result of improved angiogenesis in the eNOS-EPCs mice. These findings support the idea that physiological levels of NO exert beneficial effects in the setting of acute and chronic heart infarction. 
Endothelial dysfunction and failed angiogenesis occurs in patients with heart infarction $[18,19]$. NO has been extensively studied regarding its proangiogenic roles in endothelial homeostasis, migration, proliferation, and tube formation[20]. eNOS is present in the vascular endothelium, platelets and several other cell types that continuously produce modest amounts of NO. The loss of endothelium-derived NO could result in vascular abnormalities [20]. Therefore, a decreased expression of eNOS may contribute to the development of cardiovascular disease, including AMI. Experimental studies [21, 22] indicated that eNOSdeficient mice enhanced cardiac hypertrophy and diminished myocardial capillarization. Studies [23-25] also demonstrated that genetic deficiency of eNOS resulted in significant pulmonary hypertension and right ventricular remodeling. Furthermore, Maas R. et al. [26] found that the expression of eNOS protein in patients with AMI was markedly lower than the healthy people, an in vitro study of Kaur S et al. [27] demonstrated that eNOS-modified EPCs can improve the angiogenic properties of EPCs from patients with coronary artery disease, and studies[28, 29] also showed that elevated eNOS expression using transgenic mice with overexpression of eNOS can attenuate LV remodeling and dysfunction after AMI in mice. In the present study, mice injected with eNOS-EPCs had improved coronary vascularity compared with mice of control EPCs. These findings, in conjunction with the present results, provide significant support for a protective role of eNOS-derived NO in infarct-induced congestive heart failure.

The present data demonstrate significant beneficial effects in eNOS-EPCs transplantation during AMI. Although the mechanism of reduced infarction area appears to be related to improvement in local angiogenesis [21, 28], the mechanism of improved angiogenesis remains unclear. One possible mechanism is that implanted EPCs with eNOS overexpression are attributing to both enhanced paracrine effect and increased endothelial cell differentiation [30-32]. The increased bioavailability of NO may attenuate the loss of capillaries that occurs during AMI and may actually potentiate the formation of new vessels[33]. Angiogenesis gene, such as vascular endothelial growth factor (VEGF), basic fibroblast growth factor (bFGF) and erythropoietin (EPO), may be modulated by NO production in the process of angiogenesis [34]. In addition, the enhanced NO production in the eNOS-EPCs recipient hearts may protect against ventricular arrhythmia and reduce mortality after AMI [14]. The third potent mechanism of therapeutic effect by eNOS-EPCs may be that eNOS-EPCs could modulate local inflammation, which plays an important role in tissue damage of heart disease[35]. Thus, EPCs with eNOS overexpression play an important role to improve heart function in the setting of AMI. However, this study can explain only a small part of mechanism of AMI. Additional studies are required to elucidate the molecular mechanism by which eNOS is involved in AMI.

In conclusion, transplantation of the eNOS-EPCs significantly improves heart repair after severe AMI in mice. These data provided clear evidence of the beneficial role of eNOS enhanced EPCs during AMI. Further studies should be directed toward identifying the mechanism of this protective effect. In the future, therapies by transplantation of stem cell carrying exogenous gene might be developed to improve clinical outcomes in patients with AMI.

\section{Acknowledgements}

The authors thank Prof. Xiaoping Zhang for his expert technical assistance.

\section{Disclosure Statement}

All authors are in agreement with the content of this manuscript. The authors declare no conflict of interest. 


\section{References}

1 Lloyd-Jones D, Adams RJ, Brown TM, Carnethon M, Dai S, De Simone G, Ferguson TB, Ford E, Furie K, Gillespie C, Go A, Greenlund K, Haase N, Hailpern S, Ho PM, Howard V, Kissela B, Kittner S, Lackland D, Lisabeth L, Marelli A, McDermott MM, Meigs J, Mozaffarian D, Mussolino M, Nichol G, Roger VL, Rosamond W, Sacco R, Sorlie P, Thom T, Wasserthiel-Smoller S, Wong ND, Wylie-Rosett J: Heart disease and stroke statistics--2010 update: A report from the american heart association. Circulation 2010;121:e46-e215.

2 Dickstein K, Bebchuk J, Wittes J: The high-risk myocardial infarction database initiative. Prog Cardiovasc Dis 2012;54:362-366.

3 Silvain J, Collet JP, Nagaswami C, Beygui F, Edmondson KE, Bellemain-Appaix A, Cayla G, Pena A, Brugier D, Barthelemy O, Montalescot G, Weisel JW: Composition of coronary thrombus in acute myocardial infarction. J Am Coll Cardiol 2011;57:1359-1367.

-4 Rangappa S, Fen C, Lee EH, Bongso A, Sim EK: Transformation of adult mesenchymal stem cells isolated from the fatty tissue into cardiomyocytes. Ann Thorac Surg 2003;75:775-779.

5 Revilla A, Lopez J, Arnold R, Sanchez PL, Villa A, Pinedo M, Fernandez-Aviles F, San Roman JA: [long-term changes in left ventricular function following intracoronary stem cell transplantation for acute myocardial infarction]. Rev Esp Cardiol 2011;64:334-337.

-6 Tao Z, Chen B, Tan X, Zhao Y, Wang L, Zhu T, Cao K, Yang Z, Kan YW, Su H: Coexpression of vegf and angiopoietin-1 promotes angiogenesis and cardiomyocyte proliferation reduces apoptosis in porcine myocardial infarction (mi) heart. Proc Natl Acad Sci U S A 2011;108:2064-2069.

7 Amini AR, Laurencin CT, Nukavarapu SP: Differential analysis of peripheral blood- and bone marrowderived endothelial progenitor cells for enhanced vascularization in bone tissue engineering. J Orthop Res 2012;30:1507-1515.

8 Asahara T, Masuda H, Takahashi T, Kalka C, Pastore C, Silver M, Kearne M, Magner M, Isner JM: Bone marrow origin of endothelial progenitor cells responsible for postnatal vasculogenesis in physiological and pathological neovascularization. Circ Res 1999;85:221-228.

-9 Asahara T, Murohara T, Sullivan A, Silver M, van der Zee R, Li T, Witzenbichler B, Schatteman G, Isner JM: Isolation of putative progenitor endothelial cells for angiogenesis. Science 1997;275:964-967.

10 Chade AR, Zhu X, Lavi R, Krier JD, Pislaru S, Simari RD, Napoli C, Lerman A, Lerman LO: Endothelial progenitor cells restore renal function in chronic experimental renovascular disease. Circulation 2009;119:547-557.

11 Hu Z, Zhang F, Yang Z, Yang N, Zhang D, Zhang J, Cao K: Combination of simvastatin administration and epc transplantation enhances angiogenesis and protects against apoptosis for hindlimb ischemia. J Biomed Sci 2008;15:509-517.

12 Koiwaya H, Sasaki K, Ueno T, Yokoyama S, Toyama Y, Ohtsuka M, Nakayoshi T, Mitsutake Y, Imaizumi T: Augmented neovascularization with magnetized endothelial progenitor cells in rats with hind-limb ischemia. J Mol Cell Cardiol 2011;51:33-40.

-13 Vellimana AK, Milner E, Azad TD, Harries MD, Zhou ML, Gidday JM, Han BH, Zipfel GJ: Endothelial nitric oxide synthase mediates endogenous protection against subarachnoid hemorrhage-induced cerebral vasospasm. Stroke 2011;42:776-782.

-14 Burger DE, Lu X, Lei M, Xiang FL, Hammoud L, Jiang M, Wang H, Jones DL, Sims SM, Feng Q: Neuronal nitric oxide synthase protects against myocardial infarction-induced ventricular arrhythmia and mortality in mice. Circulation 2009;120:1345-1354.

15 de Waard MC, van Haperen R, Soullie T, Tempel D, de Crom R, Duncker DJ: Beneficial effects of exercise training after myocardial infarction require full enos expression. J Mol Cell Cardiol 2010;48:1041-1049.

16 Koskenvuo JW, Sievers RE, Zhang Y, Angeli FS, Lee B, Shih H, Ye J, Boyle AJ, Yeghiazarians Y: Fractionation of mouse bone-marrow cells limits functional efficacy in non-reperfused mouse model of acute myocardial infarction. Ann Med 2012;44:829-835.

17 Toldo S, Bogaard HJ, Van Tassell BW, Mezzaroma E, Seropian IM, Robati R, Salloum FN, Voelkel NF, Abbate A: Right ventricular dysfunction following acute myocardial infarction in the absence of pulmonary hypertension in the mouse. PLoS One 2011;6:e18102. 


\section{Cellular Physiology Cell Physiol Biochem 2013;31:355-365 and Biochemistry

18 Ahmed Z, Tang WH: Pharmacologic strategies to target oxidative stress in heart failure. Curr Heart Fail Rep 2012;9:14-22.

19 Chung NA, Lydakis C, Belgore F, Li-Saw-Hee FL, Blann AD, Lip GY: Angiogenesis, thrombogenesis, endothelial dysfunction and angiographic severity of coronary artery disease. Heart 2003;89:1411-1415.

-20 Barbato JE, Tzeng E: Nitric oxide and arterial disease. J Vasc Surg 2004;40:187-193.

21 Kazakov A, Muller P, Jagoda P, Semenov A, Bohm M, Laufs U: Endothelial nitric oxide synthase of the bone marrow regulates myocardial hypertrophy, fibrosis, and angiogenesis. Cardiovasc Res 2012;93:397-405.

22 Brede M, Roell W, Ritter O, Wiesmann F, Jahns R, Haase A, Fleischmann BK, Hein L: Cardiac hypertrophy is associated with decreased enos expression in angiotensin at 2 receptor-deficient mice. Hypertension 2003;42:1177-1182.

-23 Scherrer-Crosbie M, Ullrich R, Bloch KD, Nakajima H, Nasseri B, Aretz HT, Lindsey ML, Vancon AC, Huang PL, Lee RT, Zapol WM, Picard MH: Endothelial nitric oxide synthase limits left ventricular remodeling after myocardial infarction in mice. Circulation 2001;104:1286-1291.

-24 Fagan KA, Fouty BW, Tyler RC, Morris KG Jr, Hepler LK, Sato K, LeCras TD, Abman SH, Weinberger HD, Huang PL, McMurtry IF, Rodman DM: The pulmonary circulation of homozygous or heterozygous enos-null mice is hyperresponsive to mild hypoxia. J Clin Invest 1999;103:291-299.

25 Miller AA, Hislop AA, Vallance PJ, Haworth SG: Deletion of the enos gene has a greater impact on the pulmonary circulation of male than female mice. Am J Physiol Lung Cell Mol Physiol 2005;289:L299-306.

-26 Maas R, Schwedhelm E, Kahl L, Li H, Benndorf R, Luneburg N, Forstermann U, Boger RH: Simultaneous assessment of endothelial function, nitric oxide synthase activity, nitric oxide-mediated signaling, and oxidative stress in individuals with and without hypercholesterolemia. Clin Chem 2008;54:292-300.

$\checkmark 27$ Kaur S, Kumar TR, Uruno A, Sugawara A, Jayakumar K, Kartha CC: Genetic engineering with endothelial nitric oxide synthase improves functional properties of endothelial progenitor cells from patients with coronary artery disease: An in vitro study. Basic Res Cardiol 2009;104:739-749.

-28 Jones SP, Greer JJ, van Haperen R, Duncker DJ, de Crom R, Lefer DJ: Endothelial nitric oxide synthase overexpression attenuates congestive heart failure in mice. Proc Natl Acad Sci U S A 2003;100:4891-4896.

29 de Waard MC, van der Velden J, Boontje NM, Dekkers DH, van Haperen R, Kuster DW, Lamers JM, de Crom R, Duncker DJ: Detrimental effect of combined exercise training and enos overexpression on cardiac function after myocardial infarction. Am J Physiol Heart Circ Physiol 2009;296:H1513-1523.

-30 Hu X, Yu SP, Fraser JL, Lu Z, Ogle ME, Wang JA, Wei L: Transplantation of hypoxia-preconditioned mesenchymal stem cells improves infarcted heart function via enhanced survival of implanted cells and angiogenesis. J Thorac Cardiovasc Surg 2008;135:799-808.

-31 Iwasaki H, Kawamoto A, Tjwa M, Horii M, Hayashi S, Oyamada A, Matsumoto T, Suehiro S, Carmeliet P, Asahara T: Plgf repairs myocardial ischemia through mechanisms of angiogenesis, cardioprotection and recruitment of myo-angiogenic competent marrow progenitors. PLoS One 2011;6:e24872.

-32 Korpisalo P, Karvinen H, Rissanen TT, Kilpijoki J, Marjomaki V, Baluk P, McDonald DM, Cao Y, Eriksson U, Alitalo K, Yla-Herttuala S: Vascular endothelial growth factor-a and platelet-derived growth factor-b combination gene therapy prolongs angiogenic effects via recruitment of interstitial mononuclear cells and paracrine effects rather than improved pericyte coverage of angiogenic vessels. Circ Res 2008;103:10921099.

33 Kondo T, Kobayashi K, Murohara T: Nitric oxide signaling during myocardial angiogenesis. Mol Cell Biochem 2004;264:25-34.

34 Murohara T, Asahara T, Silver M, Bauters C, Masuda H, Kalka C, Kearney M, Chen D, Symes JF, Fishman MC, Huang PL, Isner JM: Nitric oxide synthase modulates angiogenesis in response to tissue ischemia. J Clin Invest 1998;101:2567-2578.

-35 Fleming RM: The fleming unified theory of vascular disease: A link between atherosclerosis, inflammation, and bacterially aggravated atherosclerosis (baa). Angiology 2000;51:87-89. 